\title{
A preliminary study of the behaviour of water buffaloes (Bubalus bubalis) imported to Poland (Short Communication)
}

\author{
Ireneusz Antkowiak, Jarosław Pytlewski, Anna Purczyńska and Ryszard Skrzypek \\ Department of Cattle Breeding and Milk Production, Poznań University of Life Sciences, Poznań, Poland
}

\begin{abstract}
This study was carried out on 26 adult water (river) buffaloes ( 25 females and 1 male) imported in 2006 to an eco-tourism farm in the Wielkopolska province, Poland. During the growing season, animals were kept on a logged pasture covering an area of about 15 ha. The pasture was divided into three approximately equal parts, each with a different facility available for wallowing; i.e. pond, drainage ditch and stream. Behavioural observations were carried out three times in July and August 2007 in approximately 14-d intervals, each time during one day on a different part of the pasture, always between 06.00 and 16.00 . The method of registration was instantaneous scan sampling, performed at approximately 60 -min intervals. On the days of observations mean daily temperature varied from 20.2 to $20.8^{\circ} \mathrm{C}$. Grazing was the behaviour shown by the highest percentage of animals in the herd (58.6\%), followed by rumination $(28.2 \%)$, lying down $(26.5 \%)$, wallowing $(12.9 \%)$ and standing $(1.4 \%)$. When they had access to a pond or ditch, the proportion of animals wallowing was twice as much compared to stream access $(P<0.05)$. It was concluded that the welfare of the investigated buffaloes was not compromised during the high summer temperatures that can be encountered in Poland. Results also indicate that the highest level of welfare can be reached in this time of year when animals are provided with access to ample facility for wallowing. Under our climatic conditions facilities with still or slowly moving water appeared to be preferred by river buffaloes. However, this study has a limitation which is short period of observation, thus it is possible that a longer and more representative period of observations could change these conclusions.
\end{abstract}

Keywords: water buffalo, Poland, behaviour, welfare

\section{Introduction}

The presence of water buffaloes in Poland was first mentioned in 1389, in connection with their purchase by the estate of Sędzisławice near Pińczów, located in the southern part of the country. Later data from the 16-18th centuries mentioned buffaloes as animals found in a number of sites. Their largest numbers were kept in the eastern regions, but they were also found in central and western parts (Lasota-Moskalewska 2005).

There is no written information on buffalo keeping in Poland in the 20th century. In recent years a rediscovery of the merits of water buffalo can be observed in Poland along with development of pro-ecological trends in agriculture. However, this species is believed to be 
less flexible in its adaptation to climatic conditions than cattle (Vo \& Wang 2007, Thomas 2008, Ahmad \& Tariq 2010, Czerniawska-Piątkowska et al. 2010).

Therefore the objective of this study was the evaluation of the basic behaviours in a herd of water buffaloes in Poland, which was assessed in the summer months.

\section{Material and methods}

The study was conducted on the only herd of water (river) buffaloes currently being managed in Poland. The herd was formed on the basis of 25 females aged 3-8 years, imported in September 2006 from Transylvania, Romania. In December 2006 a 3-year old bull originating from an Italian line was purchased in Germany.

The farm to which the investigated buffaloes had been imported is located in the Wielkopolska province (latitude 52.647833, longitude 15.970835) and it has the status of a certified ecological as well as agro-tourism farm. It covers an area of approximately $40 \mathrm{ha}$, and the typical agricultural area comprises mostly grassland (meadows and pastures), including around 15 ha of wetland. Meadows provide material for making hay, while the wetland is used as a pasture where animals are kept throughout the growing season. During the study, the pasture was divided using an electric fence into three approximately equal parts, each with a different facility for wallowing; i.e. a pond ( $0.8 \mathrm{ha})$, a wide $(3-4 \mathrm{~m})$ drainage ditch with very slowly running water and a narrow and shallow (about $1 \mathrm{~m}$ and $0.2-0.3 \mathrm{~m}$, respectively) fast stream. In all cases access to the facility for wallowing was ample and very easy. The pond and the ditch were deep enough for the animals to immerse their whole bodies in the water. During the period of observations the herd grazed rotationally on all three parts of the pasture. The species and availability of plants for grazing were similar on all parts. When animals were on the pasture it was a major source of food for them, and the only supplement were salt licks provided ad libitum.

Behavioural observations were performed on three selected days in 2007, between 21 July and 20 August. During the whole period of observations mean daily dry bulb temperatures, as measured at $07.00,13.00$ and 20.00 , were determined. Animals $(n=26)$ were subjected to observations in approximately 14-d intervals, each day on different part of the pasture. On each part of the pasture the observation day was selected between the 3rd and 5 th day of the rotation. The criterion for choice of the observation day was the weather, which was assumed to be sunny and hot. Observations were made once per hour in approximately 60-min intervals over a 10 -h period ( 06.00 to 16.00$)$. The method of registration was instantaneous scan sampling. The following behavioural categories were recorded: activity - grazing (biting the herbage while walking or standing) and ruminating (associated with lying, standing or wallowing); postures - standing, lying or wallowing (lying in the wallowing facility).

Data were analysed statistically using the GLM procedure of the SAS package (SAS Institute Inc., Cary, NC, USA; Freund et al. 1986) with a model containing the following fixed effects: facility for wallowing (pond, ditch, stream), time of the day (06.00-08.00, 08.00-10.00, 10.00$12.00,12.00-14.00$, and 14.00-16.00), and interaction between both main effects. Significance of differences between means within class variables was evaluated with the Duncan's multiple range test, with alpha values specified at 0.01 and 0.05 . 


\section{Results}

Mean daily temperature during the entire period of observations was $20.2^{\circ} \mathrm{C}$, while on the days of observations it was $20.8^{\circ} \mathrm{C}$ (pond), $20.2^{\circ} \mathrm{C}$ (ditch) and $20.6^{\circ} \mathrm{C}$ (stream). The highest respective daily temperatures as measured at 13.00 were 27,25 and $26^{\circ} \mathrm{C}$. Thus, all the temperatures were rather high in terms of the Polish summer and similar over the days of behavioural observations.

Table 1 shows that grazing was the behaviour that was shown by the highest percentage of animals in the herd (58.6\%), followed by rumination (28.2\%), lying (26.5\%), wallowing $(12.9 \%)$ and standing (1.4\%). The highest fraction of animals (nearly $90 \%)$ grazed during morning hours (06.00-08.00), while during other hours significantly fewer animals $(P<0.01)$ showed this type of behaviour. Rumination, lying and wallowing were the other behaviours that were associated significantly $(P<0.01)$ with period of observations. Wallowing reached its peak between 10.00-12.00 and percentage of animals showing this behaviour was also high between 08.00-10.00. Rumination was almost not observed between 06.00-08.00, whereas during the remaining hours percentage of this behaviour ranged from 25.0 to $38.5 \%$.

Table 1

Diurnal pattern of behaviours of water buffalo observed over a 10-h period

\begin{tabular}{lccccc}
\hline Hours & Grazing & Ruminating & Lying & Standing & Wallowing \\
\hline $06.00-08.00$ & $89.1 \pm 3.1^{\mathrm{A}}$ & $5.8 \pm 3.9^{\mathrm{A}}$ & $10.9 \pm 3.0^{\mathrm{Aa}}$ & 0.0 & $0.0^{\mathrm{Aa}}$ \\
$08.00-10.00$ & $46.2 \pm 3.3^{\mathrm{Ba}}$ & $38.5 \pm 4.2^{\mathrm{Ba}}$ & $35.9 \pm 8.3^{\mathrm{B}}$ & 0.0 & $19.2 \pm 7.4^{\mathrm{b}}$ \\
$10.00-12.00$ & $48.7 \pm 4.9^{\mathrm{Ba}}$ & $36.5 \pm 4.1^{\mathrm{Ba}}$ & $23.7 \pm 3.2^{\mathrm{b}}$ & $3.2 \pm 2.1$ & $24.4 \pm 5.6^{\mathrm{B}}$ \\
$12.00-14.00$ & $62.8 \pm 4.3^{\mathrm{Bb}}$ & $25.0 \pm 4.7^{\mathrm{Bb}}$ & $25.0 \pm 5.6^{\mathrm{b}}$ & $3.8 \pm 2.6$ & $7.7 \pm 3.0^{\mathrm{Aa}}$ \\
$14.00-16.00$ & $46.2 \pm 5.8^{\mathrm{Ba}}$ & $35.3 \pm 8.8^{\mathrm{Ba}}$ & $37.1 \pm 7.2^{\mathrm{B}}$ & 0.0 & $13.5 \pm 6.3$ \\
Average & $58.6 \pm 3.6$ & $28.2 \pm 3.2$ & $26.5 \pm 3.0$ & $1.4 \pm 0.7$ & $12.9 \pm 2.7$ \\
P-value & 0.0001 & 0.0001 & 0.0006 & 0.1195 & 0.0017 \\
\hline
\end{tabular}

Means for percentages of animals \pm SE, ${ }^{A B a b}$ Means with different superscripts differ significantly: ${ }^{A B} P<0.01,{ }^{\text {ab }} P<0.05$.

Table 2

Effect of facility for wallowing on behaviours of water buffalo observed over a 10-h period

\begin{tabular}{lccccc}
\hline Facility & Grazing & Ruminating & Lying & Standing & Wallowing \\
\hline Pond & $61.2 \pm 6.1$ & $26.5 \pm 6.1$ & $23.5 \pm 6.0$ & $0.8 \pm 0.8$ & $15.0 \pm 4.7$ \\
Irrigation ditch & $58.8 \pm 6.7$ & $29.6 \pm 5.3$ & $24.5 \pm 4.4$ & $0.0^{\mathrm{a}}$ & $16.5 \pm 3.2^{\mathrm{a}}$ \\
Stream & $55.8 \pm 6.3$ & $28.5 \pm 5.8$ & $31.5 \pm 5.3$ & $3.5 \pm 1.9^{\mathrm{b}}$ & $7.3 \pm 3.1^{\mathrm{b}}$ \\
$P$-value & 0.5462 & 0.6997 & 0.1131 & 0.0701 & 0.0656 \\
\hline
\end{tabular}

Means for percentages of animals $\pm \mathrm{SE}$, ab Means with different superscripts differ significantly at $P<0.05$.

Type of facility for wallowing nearly significantly $(P \sim 0.07)$ affected the percentages of animals standing and wallowing (Table 2). Standing engaged the highest part of animals when they had access to a stream. The data also indicate that when animals had access to a pond or ditch, they spent twice as much time wallowing when compared to the stream pasture. 


\section{Discussion}

Napolitano et al. (2007) and De Rosa et al. (2009) performed behavioural observations focused on the distribution of basic behaviours in a herd of grazing water buffalo during similar times of the day to those in the present study. The study by Napolitano et al. (2007) was carried out in southern Italy on buffalo heifers, aging 8-9 months at the start of observations. During summer the proportion of time spent grazing was $40.9 \%$, but it was higher in spring $(60.0 \%)$, which is very close to that observed in this study. In the springtime the percentages of animals lying $(21.0 \%)$ and wallowing (23.0\%) were also similar to our results, while the proportion of animals ruminating was lower (10.8\%). However, in the case of ruminating it must be taken into account that the cited authors observed much younger animals. Compared to the results of Napolitano et al. (2007) as well as De Rosa et al. (2009) the percentage of wallowing behaviour was 2-4 times lower in our study, although average conditions to perform this were probably much better. It is very likely that the remarkably lower proportion of buffaloes wallowing observed in the present study was a result of lower ambient temperature, which otherwise was quite high as regards the average climatic conditions of Poland. A support for this hypothesis could be the results of De Rosa et al. (2009) who found a considerable positive association between temperature on the observation day and the fraction of animals wallowing.

The 24-h pattern of grazing has not been investigated in water buffaloes. In the available literature there is also no information on wallowing preferences in the Mediterranean buffalo with respect to the facility for wallowing, although a number of authors (e.g. Borghese \& Mazzi 2005, Thomas 2008, Czerniawska-Piątkowska et al. 2010) claim that this type of buffalo prefers sources of running clear water. Our study showed that buffaloes prefer wallowing in a pond with still water or in a wide and deep irrigation ditch with slowly running water rather than a narrow and shallow stream with quickly running water. Apparently, the size and convenience of the facility were key factors meaning that different proportions of animals were wallowing. Because a higher proportion of animals lay when they had access to a stream, it seems to be further evidence that wallowing, apart from its thermoregulatory function, is also a form of relax.

Concluding, the behavioural observations performed in this study on water (river) buffaloes imported to Poland and kept round the clock on a pasture with constant access to a facility for wallowing have shown that their welfare was not compromised during high summer temperatures. Results also indicate that the highest level of welfare can be reached in this time of year when animals are provided with access to ample facility for wallowing. In our climatic conditions facilities with still or slowly moving water appeared to be preferred by river buffaloes. However, the short period of observations may have been not sufficient to have a clear picture of buffalo behaviour. It is possible that a longer and more representative period could change these conclusions. As buffaloes are native of tropical areas, further studies are needed to investigate their ability to cope with the cold winters of the Polish climate. 


\section{Acknowledgements}

The authors would like to thank Dr. Jerzy Harabasz and his wife Ingeborg, the owners of the farm, for their kind help during behavioural observations as well as for valuable comments on the manuscript.

\section{References}

Ahmad S, Tariq M (2010) Heat stress management in water buffaloes: a review. Proc 9th World Buffalo Congr, Buenos Aires, Argentina, 297-310

Borghese A, Mazzi M (2005) Buffalo population and strategies in the world. In: Borghese A (ed.) Buffalo production and research. FAO, Rome, Italy, 1-39

Czerniawska-Piątkowska E, Chociłowicz E, Szewczuk M (2010) Biology of Bubalus bubalis. Ann Anim Sci 10, 107-115

De Rosa G, Grasso F, Braghieri A, Bilancione A, Di Francia A, Napolitano F (2009) Behavior and milk production of buffalo cows as affected by housing system. J Dairy Sci 92, 907-912

Freund RJ, Littell RC, Spector PC (1986) SAS System for Linear Models. SAS Institute Inc., Cary, NC, USA

Lasota-Moskalewska A (2005) [Domestic animals in the history of mankind]. Univ Warsaw, Poland, 134-135 [in Polish]

Napolitano F, Grasso F, Saltalamacchia F, Martiniello P, Bilancione A, Pacelli C, De Rosa G (2007) Grazing behaviour of buffalo heifers. Ital J Anim Sci 6 Suppl 2, 1256-1259

Thomas CS (2008) Efficient dairy buffalo production. De Laval International AB, Tumba, Sweden

Vo TKT, Wang SC (2007) Differences in adaptation to tropical weather between buffaloes and cattle. Ital J Anim Sci 6 Suppl 2, 1340-1343

Received 5 October 2011, accepted 20 March 2012.

Corresponding author:

Ryszard Skrzypek

email: skrzypek@jay.up.poznan.pl

Department of Cattle Breeding and Milk Production, Poznań University of Life Sciences, Wojska Polskiego Str. 71 A, 60-625 Poznań, Poland 